\title{
Originals
}

\section{Serum Glibenclamide in Diabetic Patients, and Influence of Food on the Kinetics and Effects of Glibenclamide}

\author{
G. Sartor, A. Melander, B. Scherstén, and E. Wåhlin-Boll \\ University of Lund, Department of Medicine, Lund University Hospital, Lund, Department of Clinical Pharmacology, \\ Malmö General Hospital, Malmö, and Department of Community Care Sciences, Dalby, Sweden
}

Summary. The steady state concentrations of glibenclamide in serum were measured radioimmunologically in 37 diabetic patients after administration for at least a year. No other antidiabetic drugs had been given. The interindividual variation in glibenclamide concentrations was extremely large $(0$ to $1520 \mathrm{nmol} / \mathrm{l}$ ), greatly exceeding the variation in dosage (2.5-25 mg daily). There was no relation between dose and serum concentration of glibenclamide. Only four ( $9 \%$ ) patients had fasting blood glucose concentrations below $5.5 \mathrm{mmol} / \mathrm{l}$, and fewer than half had values below $8 \mathrm{mmol} / \mathrm{l}$. In most cases, therefore, the therapy was inadequate. Single-dose kinetics of glibenclamide was assessed in healthy volunteers. Food intake did not influence the bioavailability of a $5 \mathrm{mg}$ dose of glibenclamide. There was no insulin increase in response to glibenclamide unless a meal was also given, and this increase was not significant until $1 \mathrm{~h}$ after administration of drug and meal, when the mean serum concentration of glibenclamide had reached $100 \mathrm{nmol} / \mathrm{l}$. Even in the fasting state, however, there was a progressive fall in blood glucose after glibenclamide administration, significant within $45 \mathrm{~min}$ and with a nadir at $2-2^{1 / 2} \mathrm{~h}$.

Key words: Diabetes mellitus, sulphonylurea, glibenclamide, steady state levels, bioavailability, food intake, plasma insulin, blood glucose.

The earlier sulphonylurea drugs, such as tolbutamide and chlorpropamide, have been subject to considerable criticism in the long-term management of diabetes mellitus $[1,2]$. Recent investigations have shown that the steady-state concentrations of these two drugs in plasma are subject to great interindividual differences, suggesting that the therapeutic use of tolbutamide and chlorpropamide is far from optimal [3]. These observations promoted interest in the interindividual variations of the steady-state concentrations of one of the later sulphonylureas, glibenclamide, which has been examined in the present study.

Another point of interest is the possible influence of food intake on the kinetics and effects of glibenclamide. Studies on another second generation sulphonylurea (glipizide) have shown that its effect on blood glucose is more pronounced when the drug is taken before meals than when taken with meals [4], and subsequent studies indicate that concomitant food intake delays glipizide absorption [5]. In addition, food has been found to exert a significant influence on the bioavailability of many other drugs, such as beta adrenoceptor antagonists, hydralazine, hydrochlorothiazide, spironolactone, phenytoin, dicoumarol, and various chemotherapeutic agents [6]. For these reasons, the current investigation included a study on the influence of a standardised breakfast on the single-dose kinetics and effects of glibenclamide in healthy volunteers.

\section{Materials and Methods}

\section{Diabetic Patients}

Thirty-seven patients with maturity-onset diabetes mellitus were studied. Their mean ages and per cent ideal body weights were 65.3 ( \pm SD 11.9) years (range 41-84), and 108.2 ( \pm SD 18.9) per cent (range 72.8-164.4). They were regular attenders at the Medical Clinic, Lund University Hospital, or at the Community Care Center, Dalby. Twelve patients had impaired renal function, as defined by serum creatinine concentrations over $115 \mathrm{mmol} / 1$. None had detectable hepatic or endocrine disease apart from diabetes. All had conventional dietary restrictions and had been receiving glibenclamide (Euglucon ${ }^{\circledR}$ or Daonil ${ }^{\circledR}$, Boehringer-Mannheim $\mathrm{GmbH}$, Mannheim, and Hoechst AG, Frankfurt/Main, 


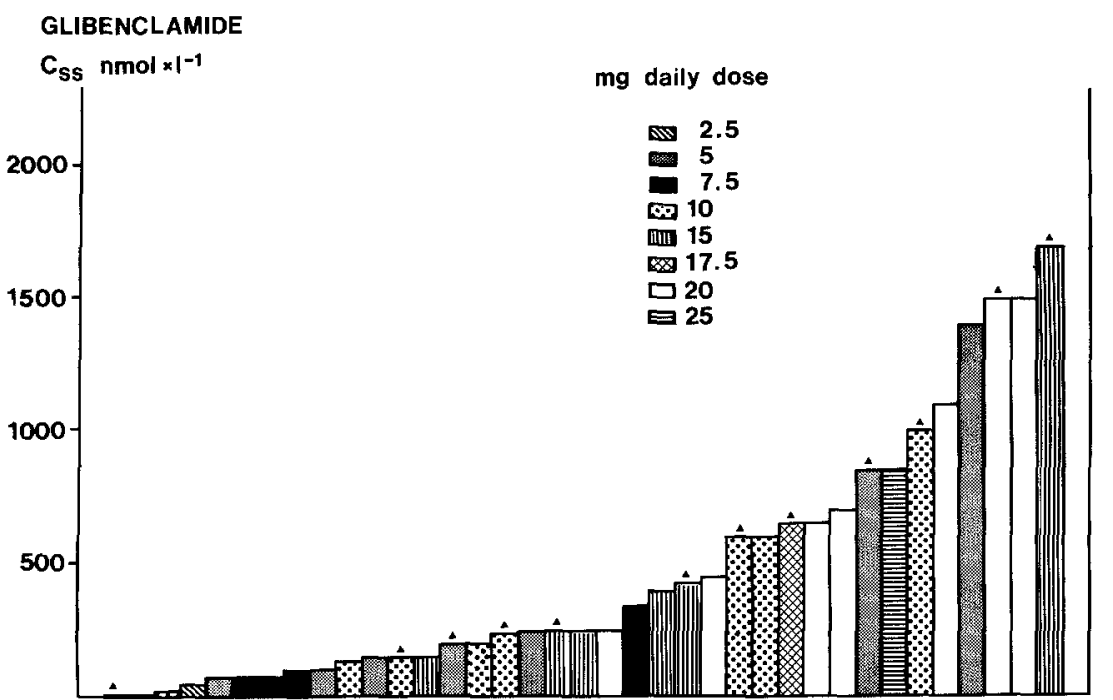

Fig. 1. Steady state concentrations (Css) of serum glibenclamide in 37 patients with diabetes mellitus treated with the drug for at least one year. Triangles indicate patients with impaired renal fuction (serum creatinine $>115 \mu \mathrm{mol} / \mathrm{l}$ )
Federal Republic of Germany) for at least 1 year. In order to avoid changes in eating habits and in drug compliance, the patients were not informed about the study. Blood samples were taken at about 8 a.m., after overnight fasting, when the patients came for their regular check-ups. They had been asked to abstain from their morning dose of the drug on the day of the visit. None of the patients were taking any other antidiabetic drugs.

\section{Healthy Volunteers}

Nine male volunteers served as test subjects. They were all healthy, according to clinical examinations and routine blood tests. Their mean ages and per cent ideal body weights were $26( \pm$ SD 1.9 ) years (range $23-28$ ), and 92.8 ( \pm SD 5.3) per cent (range 84.2-100.2). Each subject was extensively informed about the investigation and gave written consent. The investigation was approved by the Ethical Committee of the University of Lund.

After 10 hours of fasting $(2200 \mathrm{~h}$ to $0800 \mathrm{~h})$, each subject came to the laboratory on three different momings, with intervals of at least one week. They were then given a) a standard meal alone, b) $5 \mathrm{mg}$ glibenclamide together with the meal, and c) $5 \mathrm{mg}$ glibenclamide alone. The drug was given as single tablets, all of the same brand and batch (Euglucon ${ }^{\mathrm{a}}$, Boehringer-Mannheim GmbH, Mannheim, Federal Republic of Germany). The standardised meal consisted of $400 \mathrm{ml}$ low-fat milk, two slices $(20 \mathrm{~g})$ of white bread with $5 \mathrm{~g}$ butter, and $150 \mathrm{ml}$ non-sweetened black coffee; $1800 \mathrm{~kJ}$ $(430 \mathrm{kcal})$. Apart from the standardised meal, no food or liquid was allowed until $4 \mathrm{~h}$ after initiation of the experiment. Thus, when only glibenclamide was given, the subjects fasted for $4 \mathrm{~h}$ in addition to the preceding $10 \mathrm{~h}$ (overnight) fasting period.

\section{Laboratory Procedures}

Serial blood samples were obtained through an indwelling antebrachial venous polyethene catheter. Blood glucose and plasma insulin were determined at regular intervals during the first $3 \mathrm{~h}$ of the experiment. Serum glibenclamide, when present, was measured at regular intervals for $24 \mathrm{~h}$.

Serum concentrations of glibenclamide were measured by a sensitive radioimmunoassay technique [7]. The antibody reacts not only with glibenclamide but also with its hydroxylated metabolite. However, as the latter is present only in minute amounts and has a very short half-life [7], its interference is probably minor or negli- gible. The sensitivity was $20 \mathrm{nmol} / \mathrm{l}$. The interassay variation was $9.9 \%$ (SD, as judged from 12 consecutive assays). Blood glucose concentrations were determined by the hexokinase method [8], and plasma insulin concentrations were measured by a commercial solid phase radioimmunoassay [9] (Phadebas Insulin-Test ${ }^{\mathrm{B}}$, Pharmacia, Uppsala, Sweden).

\section{Calculations}

The concentrations of serum glibenclamide, plasma insulin and blood glucose were plotted against time. For the drug, the peak concentrations $\left(C_{\max }\right)$ and time to peak concentrations $\left(t_{\max }\right)$ were estimated from the graphs. The elimination half-life and area under the serum concentration curve values from 0 to $8 \mathrm{~h}$ were calculated by conventional methods. Areas under the curve (from 0 to $3 \mathrm{~h}$ ) were also calculated for plasma insulin and for blood glucose. In the latter case, both the incremental area (from $0 \mathrm{~h}$ to the estimated time of intercept with the initial level) and the decremental area (from the intercept to $3 \mathrm{~h}$ ) were calculated.

\section{Statistics}

Statistical calculations were carried out by Student $t$-tests. Standard deviations are indicated by SD.

\section{Results}

\section{Diabetic Patients}

Of the 37 patients on regular glibenclamide medication, 13 were taking the drug once daily (in the morning), while 22 had a twice-daily (morning and noon), and 2 a thrice-daily regimen (morning, noon and evening, not later than $1900 \mathrm{~h}$ ). The total daily dosages were $2.5 \mathrm{mg}(\mathrm{n}=2), 5 \mathrm{mg}(8), 7.5 \mathrm{mg}(4)$, $10 \mathrm{mg}$ (8), $15 \mathrm{mg}(6), 17.5 \mathrm{mg}(1), 20 \mathrm{mg}(7)$, and $25 \mathrm{mg}$ (1) (Fig. 1). Thus, there was a 10-fold variation in daily dosage, the mean being $11.6 \mathrm{mg}$. There 


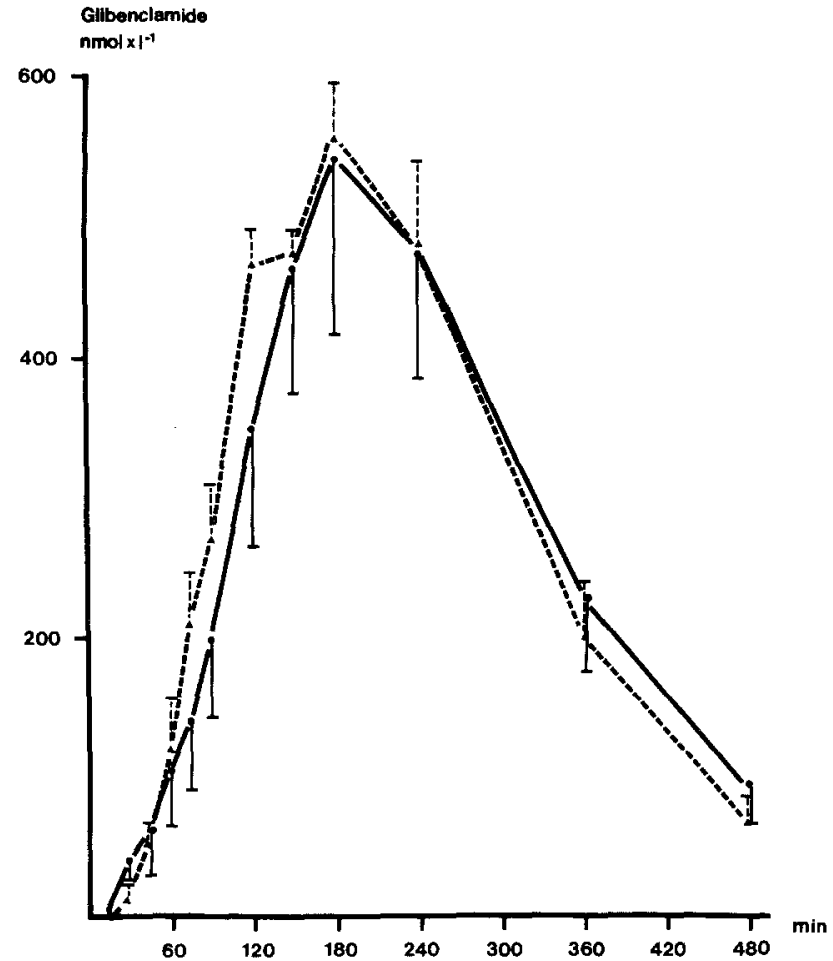

Fig. 2. Mean (and SEM) glibenclamide concentrations in serum in nine healthy volunteers taking a single oral dose $(5 \mathrm{mg})$ both on an empty stomach (-) and together with a standardised breakfast ( $\mathbf{\Delta}$ - - - $\mathbf{\Delta}$ ). No significant pre- vs. postprandial difference was recorded whether between peak concentrations $\left(C_{\max }\right)$, time to peak concentrations $\left(t_{\max }\right)$, elimination half-lives $\left(t_{1 / 2}\right)$ or areas under the concentration curves. The mean kinetic data are given in Table 1

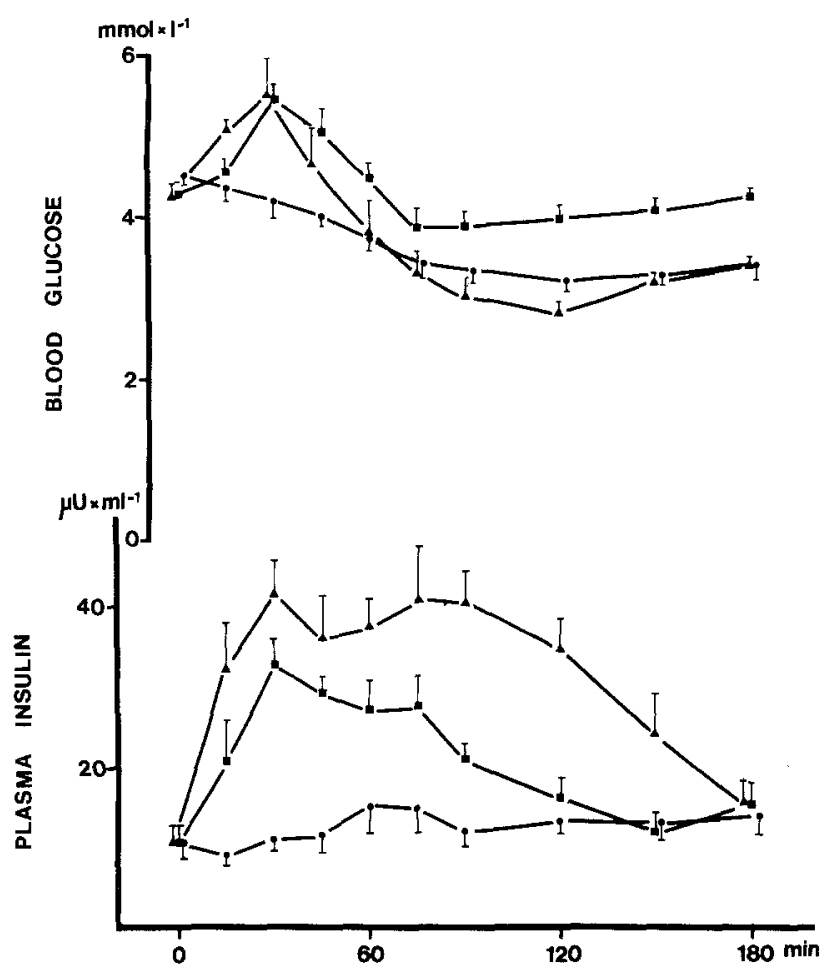

Fig. 3. Mean (and SEM) concentrations of plasma insulin (lower panel) and blood glucose (upper panel) in nine healthy volunteers given only standardised breakfast ( $\mathbf{\square}-\mathbf{\square})$, glibenclamide (5 mg) together with the meal $(\mathbf{\Lambda}-\mathbf{\Lambda})$, and only glibenclamide $(-)$

Table 1. Mean kinetic parameters ( \pm SD) of glibenclamide in nine healthy volunteers after ingestion of $5 \mathrm{mg}$ of the drug both on an empty stomach and together with a standardised meal. $\mathrm{C}_{\max }=$ peak concentration, $\mathrm{t}_{\max }=$ time to peak concentration, $\mathrm{t}_{1 / 2}=$ elimination half-life

\begin{tabular}{|c|c|c|c|c|c|}
\hline & $\begin{array}{l}\mathrm{C}_{\max } \\
(\mathrm{nmol} / \mathrm{l})\end{array}$ & $\begin{array}{l}\mathrm{t}_{\max } \\
(\min )\end{array}$ & $\begin{array}{l}t_{1 / 2} \\
(\min )\end{array}$ & $\begin{array}{l}\text { Area under the serum } \\
\text { concentration curve } \\
(\text { AUC) } \\
\left(\mathrm{nmol} \times \min \times \mathrm{ml}^{-1}\right)\end{array}$ & $\begin{array}{l}\text { AUC ratio } \\
\text { preprandial } \\
\text { postprandial }\end{array}$ \\
\hline Preprandial & $637.9 \pm 321.2$ & $203.3 \pm 68.4$ & $102.0 \pm 41.2$ & $136.4 \pm 62.9$ & - \\
\hline Postprandial & $587.7 \pm 121.9$ & $173.3 \pm 55.7$ & $95.2 \pm 19.5$ & $136.4 \pm 32.2$ & $1.03 \pm 0.54$ \\
\hline
\end{tabular}

Significance of difference between preprandial and postprandial conditions (paired $t$-tests on intra-individual data pairs): N.S. for each parameter

was no significant correlation between dosage and body weight.

The serum concentrations of glibenclamide at steady state varied greatly between the patients (Fig. 1), the extreme values being zero and $1520 \mathrm{nmol} / 1$, respectively. The mean ( $\pm \mathrm{SD}$ ) serum concentration was $478( \pm 478) \mathrm{nmol} / \mathrm{l}$. There was no significant correlation between dosage and serum concentration whether before or after correction for body weight $(r=0.48)$. The variation was also not related to differences in dose intervals: the patients taking $5.0 \mathrm{mg}$ once daily $(\mathrm{n}=7)$ showed a concentration range of $0-700 \mathrm{nmol} / \mathrm{l}$, while that in those on $5 \mathrm{mg}$ twice daily $(\mathrm{n}=5)$ was $9-300 \mathrm{nmol} / \mathrm{l}$, and in those on $10 \mathrm{mg}$ twice daily $225-750 \mathrm{nmol} / \mathrm{l}$.

Fasting blood glucose levels varied from 4.0 to $18.4 \mathrm{mmol} / \mathrm{l}$, with a mean $( \pm \mathrm{SD})$ of $9.2( \pm 3.4)$ $\mathrm{mmol} / \mathrm{l}$. Only four $(9 \%)$ of the 37 patients had normal fasting blood glucose levels $(\leq 5.5 \mathrm{mmol} / \mathrm{l})$, and fewer than half had values below $8 \mathrm{mmol} / \mathrm{l}$. There 
Table 2. Mean incremental areas (arbitrary units, \pm SD) of plasma insulin concentration curves and mean ( \pm SD) net sums of incremental (from 0 to base-line intercept) and decremental (from first intercept to the next one) areas of blood glucose concentration curves in response to a standardised meal $(M)$, and to glibenclamide taken together with the meal $(G+M)$

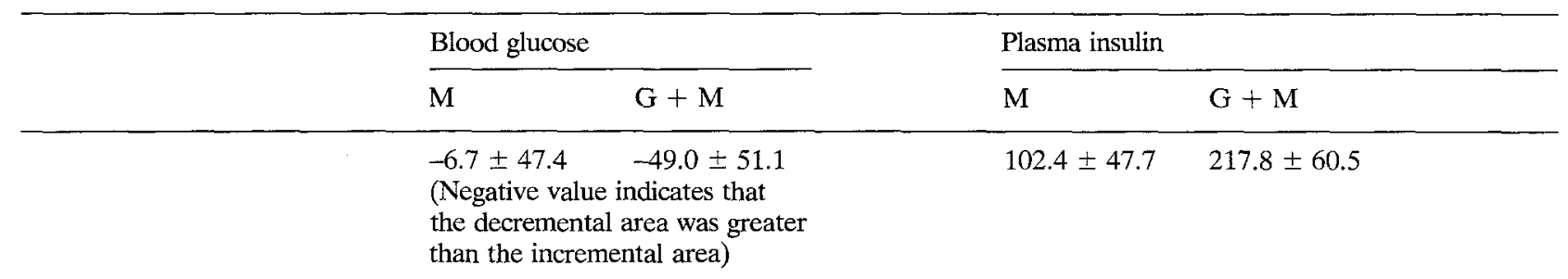

Statistical

significance of

difference between $M$

and $\mathrm{G}+\mathrm{M}$ (paired $t$-tests

on intraindividual

data pairs)

$\mathrm{p}<0.01$

$\mathrm{p}<0.001$

was no significant correlation between the serum concentrations of glibenclamide and the fasting blood glucose levels $(\mathrm{r}=0.07)$.

Twelve patients had serum creatinine concentrations above $115 . \mu \mathrm{mol} / \mathrm{l}$, with a mean $( \pm \mathrm{SD})$ of 142 $( \pm 42) \mu \mathrm{mol} / \mathrm{l}$. The remaining 25 patients had normal values $(\leqslant 115 \mu \mathrm{mol} / \mathrm{l})$. There was no significant difference in the mean daily dosages or in mean body weight between these two groups. The mean values of serum glibenclamide (Fig. 1) and blood glucose were not significantly higher in the group with elevated creatinine values than in that with normal values.

\section{Healthy Volunteers}

Serum Glibenclamide: The mean serum concentrations of glibenclamide during pre- and postprandial conditions are shown in Figure 2, and the mean kinetic data are given in Table 1.

Both preprandially and postprandially, the peak concentrations of glibenclamide occurred at about 2-4 hours after ingestion of the tablet, and the elimination half-life values $\left(t_{1 / 2}\right)$ varied from 1 to 3 hours (Table 1). When preprandial and postprandial conditions were compared, neither peak concentrations, time to reach peak concentrations, elimination halflives, nor area under the curve values displayed any significant differences, as judged from paired t-tests.

Plasma Insulin: When glibenclamide was taken with the standardised meal, the area under the plasma insulin curve was significantly greater $(p<0.001)$ than when only the meal was given (Fig. 3). The mean insulin concentrations did not differ significantly until 60 minutes $(p<0.01)$ after drug administration, when the mean serum concentration of glibenclamide was above $100 \mathrm{nmol} / \mathrm{l}$. After administration of glibenclamide without the meal, there was no consistent increase in plasma insulin (Fig. 3).

Blood Glucose: Ingestion of breakfast promoted a rapid increase in blood glucose concentration (Table 2). When glibenclamide was added to the meal, the net area under the curve was significantly smaller than when only the meal was given $(\mathrm{p}<0.05)$ (Fig. 3). The mean glucose concentration did not differ significantly until 90 minutes $(p<0.05)$ after administration of drug and meal. When only the drug was given, however, blood glucose concentration was significantly $(\mathrm{p}<0.05)$ reduced already within $45 \mathrm{~min}$, and there was then a progressive reduction from the initial value of $4.5 \mathrm{mmol} / 1$ to a nadir of $3.2 \mathrm{mmol} / 1$ at 120 and $150 \mathrm{~min}(\mathrm{p}<0.001)$ (Fig. 3).

\section{Discussion}

The most striking observation in this study was the large interindividual difference in the steady state concentrations of glibenclamide, from zero to above $1500 \mathrm{mmol} / 1$. This greatly exceeded the variation in dosage; indeed, there was no correlation between steady-state concentration and dose, whether before or after correction for body weight. Moreover, the variation could not be related to differences in dose intervals. Similarly large interindividual variations in steady-state concentrations have previously been observed for two sulphonylurea drugs of the first generation, namely, tolbutamide and chlorpropamide [3].

There are many possible explanations for these large differences. The first is a variable patient com- 
pliance, and there is evidence to suggest that this is a significant problem $[3,10,11]$. In addition, the pronounced inter-subject variation in drug-oxidising capacity known to influence the biotransformation of many drugs, i.e. beta-adrenoceptor blockers [12], nortriptyline [13], and phenytoin [14], is likely to produce a wide scatter in blood glibenclamide levels: like tolbutamide, glibenclamide is extensively metabolised by oxidation $[15,16]$. Interindividual differences in renal excretion of glibenclamide may play a role; the drug concentrations tended to be elevated in the group with impaired renal function. In a single-dose study, a slightly prolonged elimination rate of glibenclamide has been recorded in patients with renal failure [17]. It cannot be excluded, however, that these findings reflect delayed excretion of the more polar hydroxylated glibenclamide metabolite, which was not separated from the parent compound in the assay used.

Irrespective of cause, the fact that the steadystate concentrations of glibenclamide differed so extensively between patients suggests that the conventional use of this drug is far from optimal, which, in turn, may be one of the reasons why the long-term therapeutic effect of sulphonylureas is sometimes insufficient [3]. Indeed, only four of the 37 patients in the present study had normal fasting blood glucose values, and less than half had values below $8 \mathrm{mmol} / \mathrm{l}$. Similar results were obtained in a previous study with tolbutamide and chlorpropamide [3].

These and the present findings argue in favour of a much more individualised dosage of sulphonylureas than is currently employed. A crucial question is whether there exists an inverse relationship between the steady-state concentrations of the sulphonylureas and the blood glucose levels. Such a correlation should not be sought unless dietary regimes and other factors influencing blood glucose are standardised. In the present study, this was avoided as far as the patients were concerned, because the aim was to elucidate the therapeutic effect during conventional routines. The volunteers, on the other hand, had a standardised intake of food. When the drug was taken together with the meal, the volunteers displayed a significant increase in plasma insulin when the mean serum glibenclamide level had reached $100 \mathrm{nmol} / 1$. In addition, it has been reported previously that the minimal effective serum glibenclamide level is about $60 \mathrm{nmol} / 1$ [17]. It must be emphasised however, that the stimulatory effect of glibenclamide and other sulphonylureas on insulin release increases with increasing blood glucose $[18,19]$. In the present study, this was illustrated by the finding that there was a clear-cut effect of glibenclamide on insulin release when the drug was taken with the meal, but virtually no insulin increase in response to the drug when it was taken while fasting.

Although there was no insulin increase in response to glibenclamide during fasting conditions, there was a reduction in blood glucose concentration, significant within $45 \mathrm{~min}$. This may reflect an extrapancreatic effect of glibenclamide [20]; it is also possible that sulphonylureas reduce the efflux of glucose from the liver by increasing the hepatic uptake of insulin.

In addition to its direct interaction with sulphonylurea by way of blood glucose, food intake may indirectly influence glucose disposition by affecting the pharmacokinetics of these drugs. Thus, food intake has been found to reduce the rate of absorption of glipizide [5], and it has been shown that the blood glucose lowering effect of this drug is more pronounced when it is taken half an hour before the meal than when taken together with the meal [4]. In the present study, food intake influenced neither the rate of absorption, peak concentration, elimination rate, nor the extent of bioavailability of glibenclamide. Hence, there is no kinetic basis for administration of glibenclamide before meals. This kind of regime may nevertheless be rational, since it could result in a better timing between insulin release and the blood glucose increase in response to the meal. This possibility is under current investigation.

In conclusion, it seems reasonable to state that glibenclamide dosage should be more individualised than is currently practised. In addition, appropriate fractionation of the daily dose and scrutiny of the temporal relation between drug administration and intake of meals may be important.

Acknowledgement. Glibenclamide antibodies and radiolabelled glibenclamide were generously provided by Prof. Dr. F. H. Schmidt and Dr. V. Hrtska at the Boehringer-Mannheim Research Laboratory. This is gratefully acknowledged.

The study was supported by grant no. 04X-05657 from the Swedish Medical Research Council, by a grant from the Swedish Board of Health and Welfare (the Dalby project), and by a grant from Boehringer-Mannheim GmbH, Mannheim, Federal Republic of Germany.

\section{References}

1. Shen, S.-W., Bressler, R.: Clinical Pharmacology of oral antidiabetic agents (first of two parts). N. Engl. J. Med. 296, 493-497 (1977)

2. Shen, S.-W., Bressler, R.: Clinical Pharmacology of oral antidiabetic agents (second of two parts). N. Engl. J. Med. 296, 787-793 (1977)

3. Melander, A., Sartor, G., Wåhlin-Boll, E., Scherstén, B., Bitzen, P. O.: Serum tolbutamide and chlorpropamide concentrations in patients with diabetes mellitus. Br. Med. J. $1978 \mathrm{I}$, $142-144$ 
4. Sartor, G., Scherstén, B., Melander, A.: Effects of glipizide and food intake on the blood levels of glucose and insulin in diabetic patients. Acta Med. Scand. 203, 211-214 (1978)

5. Wåhlin-Boll, E., Sartor, G., Melander, A., Scherstén, B.: (in preparation)

6. Melander, A.: Influence of food on the bioavailability of drugs. Clin. Pharmacokinet. 3, 337-351 (1978)

7. Hrtska, V. E., Schmidt, F. M.: Radioimmunologische Bestimmung von Glibenklamid (Abstract). 8. Kongress der deutschen Diabetes-Gesellschaft, München 1973

8. Coburn, H. J., Carrol, J. J.: Improved manual and automated colorimetic determination of serum glucose, with use of hexokinase and glucose-6-phosphate dehydrogenase. Clin. Chem. 19, 127-130 (1973)

9. Wide, L., Axén, R., Porath, J.: Radioimmunosorbent assay for proteins. Chemical couplings of antibodies to insoluble Dextran. Immunochemistry 4, 381-386 (1967)

10. Eshelman, F. N.: Drug compliance in diabetics (Letter to the Editor). Br. Med. J. 1978 I, 581

11. Melander, A.: Drug compliance in diabetics (Letter to the Editor). Br. Med. J. 1978 I, 990

12. Johnsson, G., Regărdh, C.-G.: Clinical pharmaçokinetics of $\beta$-adrenoceptor blocking drugs. Clin. Pharmacokinet. 1, 233-263 (1976)

13. Alexandersson, B., Sjöqvist, F.: Interindividual differences in the pharmacokinetics of monomethylated tricyclic antidepressants: role of genetic and environmental factors and clinical importance. Ann. N.Y. Acad. Sci. 179, 739-751 (1971)

14. Lund, L.: Effects of phenytoin in patients with epilepsy in relation to its concentration in plasma. In: Biological effects of drugs in relation to their plasma concentrations. Davies, D. S.,
Pritchard, B. N. C. (Eds.), pp. 227-238. London: Macmillan 1973

15. Thomas, R. C., Ikeda, G. J.: The metabolic fate of tolbutamide in man and in the rat. J. Med. Chem. 9, 507 (1966)

16. Rupp, W., Christ, O., Heptner, W.: Resorption, Ausscheidung und Metabolismus nach intravenöser und oraler Gabe von $\mathrm{HB}$ $419-{ }^{14} \mathrm{C}$ an Menschen. Arzneim. Forsch. 19, 1428-1434 (1969)

17. Schmidt, F. H.: Plasma levels and excretion of glibenclamide in renal insufficiency. Atti delle giornate di diabetologia del Mediterraneo, pp. 1-18. Milano: Boehringer Biochemia s.r.l, 1975

18. Widström, A., Cerasi, E.: On the action of tulbutamide in normal man. II. Modulation of glucose-induced insulin release by tolbutamide. Acta Endocrinol. (Kbh.) 72, 519-531 (1973)

19. Grill, V., Cerasi, E.: Interacting effects of sulfonylureas and glucose on cyclic AMP metabolism and insulin release in pancreatic islets of the rat. J. Clin. Invest. 61, 1346-1354 (1978)

20. Feldman, J.M., Lebovitz, H.E.: Appraisal of the extrapancreatic actions of sulfonylureas. Arch. Intern. Med. 123, 314 (1969)

Received: December 22, 1978 ,

and in revised form: July 16, 1979

Gunnar Sartor, M. D.

Department of Medicine

Lund University Hospital

S-221 85 Lund

Sweden 